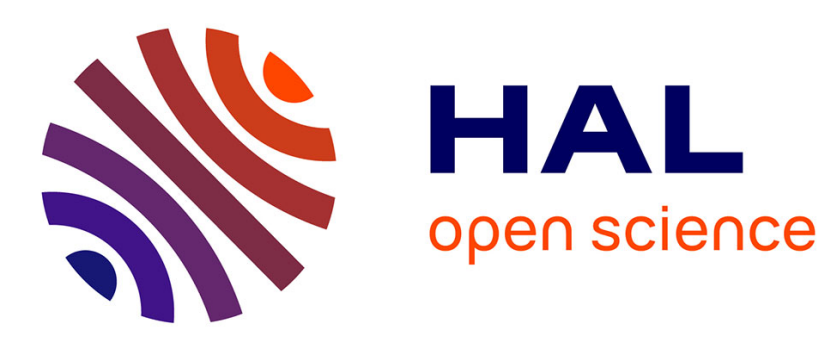

\title{
Are Emotions Evaluative Modes?
}

Jérôme Dokic, Stéphane Lemaire

\section{To cite this version:}

Jérôme Dokic, Stéphane Lemaire. Are Emotions Evaluative Modes?. Dialectica, 2015, 69 (3), pp.271292. 10.1111/1746-8361.12117. hal-02973358

\section{HAL Id: hal-02973358 https://hal-univ-rennes1.archives-ouvertes.fr/hal-02973358}

Submitted on 21 Oct 2020

HAL is a multi-disciplinary open access archive for the deposit and dissemination of scientific research documents, whether they are published or not. The documents may come from teaching and research institutions in France or abroad, or from public or private research centers.
L'archive ouverte pluridisciplinaire HAL, est destinée au dépôt et à la diffusion de documents scientifiques de niveau recherche, publiés ou non, émanant des établissements d'enseignement et de recherche français ou étrangers, des laboratoires publics ou privés. 


\title{
Are Emotions Evaluative Modes?
}

( Dialectica 69.3 pp.271-292. 2015)

Jérôme Dokic (EHESS, IJN)

$\&$

Stéphane Lemaire (Université de Rennes 1, IJN)

\begin{abstract}
Following Meinong, many philosophers have been attracted by the view that emotions have intrinsically evaluative correctness conditions. On one version of this view, emotions have evaluative contents (the Perception View). On another version, emotions are evaluative attitudes; they are evaluative at the level of intentional mode rather than content (the Attitudinal View). We raise objections against the latter version, showing that the only two ways of implementing it are hopeless. Either emotions are manifestly evaluative or they are not. In the former case, the Attitudinal View threatens to collapse into the Perception View or any other view according to which emotions are evaluative at the level of content. In the latter case, the Attitudinal View does not stand up to an obvious alternative, namely that emotions can only be assessed with respect to extrinsic (moral, prudential, aesthetical, etc.) norms or conditions of correctness.
\end{abstract}




\section{Introduction}

We commonly judge that an emotion is fitting, appropriate or correct in specific circumstances. We also consider that some objects can make an emotion fitting even if this emotion is not fitting from an all in all perspective. For instance, even if it is all in all unfitting to laugh at a joke during a funeral, we may judge that the laughter or amusement fits the joke since the joke is funny. ${ }^{1}$ In short, it seems that everybody at least implicitly agrees that emotions have fittingness conditions. Furthermore, we spontaneously express these fittingness conditions in an evaluative vocabulary. Fear in general fits dangerous objects, and admiration admirable ones.

Given this much, one may wonder what explains this evaluative practice. Why are we assessing our emotions as more or less fitting responses to values? Following the Meinongian tradition, one may suggest that this flows from the deeper fact that emotions have correctness conditions that are intrinsic to their very nature. Fittingness or appropriateness would thus be understood in terms of correctness: fear is correct as a response to danger because the nature of fear, and of emotions in general, is such that it has specific correctness conditions. One classical way of construing this suggestion is to claim that emotions have evaluative intentional contents. In this context, emotions have once been identified with evaluative judgments. This view is often called Cognitivism in the philosophical literature on emotions. Although it was well received in the '90s (see Solomon 1993, Nussbaum 2001), it has later been mostly rejected on the grounds that emotions are not mere cognitive states but genuine experiences that include a whole bodily phenomenology and maybe even some cognitive phenomenology. Moreover, the conflict that we face when we are afraid of a spider while judging that the spider is not dangerous seems much closer to a case of illusory perception than to a case of conflicting judgments or beliefs (Tappolet 2000, Döring 2009).

This has prompted the emergence ${ }^{2}$ around the turn of the twenty-first century of the Perceptual View, according to which emotions are perceptions with evaluative contents. According to this view, when we undergo an emotion, we perceive its object as having

\footnotetext{
${ }^{1}$ A point that has been well articulated by D'Arms and Jacobson (2000).

${ }^{2}$ Or at least the re-emergence since at least Scheler (1970) may be considered as defending the Perceptual View.
} 
evaluative properties (cf. Tappolet 2000, D'Arms and Jacobson 2000). Again, such a view would explain in terms of intrinsic evaluative correctness conditions why emotions are assessed as fitting or not. However, the Perceptual View faces its own difficulties. In particular, several authors (Whiting 2012, Brady 2010, Deonna and Teroni 2012, p. 69, Dokic and Lemaire 2013) have doubted that emotions do really present an object, event or state of affairs as having an evaluative property. More specifically, one might wonder which aspect of the emotional experience is able to present evaluative properties. Are we not here overburdening the content of emotion? In addition, the Perceptual View can hardly accommodate the fact that the cognitive basis of emotions is often not perceptual. Indeed, if your fear is triggered by the belief that nuclear weapons are disseminated in numerous places in the world, it is hard to understand in what sense your experience of fear attributes to this state of affairs, which is not perceptually presented, an evaluative property that is perceptually presented.

As a response to these difficulties, an interesting move has recently been suggested, which is to consider that emotions are not evaluative at the level of their contents while still being evaluative attitudes. On this view, emotions' correctness conditions would be determined not by their contents alone, but by their contents and the kinds of attitudes that they are, that is, more precisely, the emotional types to which they belong. As a result, fear and admiration as distinct attitudes would have distinct evaluative correctness conditions even though they could have the same non-evaluative content (one can either fear or admire the violence of a fighter). They would have different complete correctness conditions: they would bring the same contribution to these conditions by their identical content but different contributions given their different emotional types. We call this view the Attitudinal View after Deonna and Teroni (2012) who have recently offered a detailed version of it (which they call "the attitudinal theory of emotions"). ${ }^{3}$

In this essay, our main aim is to level objections against the Attitudinal View. Our starting point in the next section is to emphasize that two versions of the view must be distinguished insofar as the evaluative dimension of emotions may be understood as being

\footnotetext{
${ }^{3}$ Deonna and Teroni present the Attitudinal View as an instance of a broader perspective on mental states, where different types of mental states have their own "formal objects" (Mulligan 2007). Those mental states which are often believed to possess a formal object are often regarded as attitudes of considering (taking, accepting, acknowledging) their object as exemplifying the corresponding formal object: for instance, belief or judgment is a considering (taking, etc.) a proposition as true. Similarly, fear is understood as a considering (taking, etc.) a certain (typically non-propositional) object as dangerous. Here we do not assess the broader perspective but just its application to emotions.
} 
either manifest or opaque to the subject. In the first case (which we call the Manifest Attitudinal View), emotions manifestly are evaluative attitudes. However, we show that it is unclear how emotions could have an evaluative phenomenology without somehow presenting values to the subject. That is, this version of the Attitudinal View threatens to collapse into the Perceptual View, overburdening the contents of emotions after all. In the second case (which we call the Opaque Attitudinal View), emotions are evaluative attitudes but are not manifestly so. Being aware of an emotion does not make us aware of its evaluative dimension. ${ }^{4}$ However, this view raises an immediate suspicion: if the experience of an emotion does not make us aware of its evaluative nature, how do we come to know this evaluative nature? Or, to present it otherwise, how are we able to move from an emotion to an evaluative judgment if the emotion experienced conveys no evaluative information? Surely, we have to build on some other information; there must be some informational enrichment in the process leading to the judgment. But if this is so, the Opaque Attitudinal View must show that this evaluative informational enrichment derives from the apprehension of the intrinsic evaluative nature of the emotion and not from external considerations. If this cannot be done, then the Opaque Attitudinal View will be committed to the paradoxical thesis according to which emotions have intrinsic evaluative correctness conditions although they play no role in our understanding of emotions and in our forming evaluative judgments from them.

Our conclusion will be that the Attitudinal View is not after all a very promising retreat from the Perceptual View and that the problem it faces in one or the other of its versions should help to free us from the idea that emotions involve intrinsic norms or correctness conditions.

\section{How to spell out the Attitudinal View?}

Like Cognitivism and the Perceptual View, the Attitudinal View contends that emotions have intrinsic evaluative correctness conditions. The common idea underlying all three views is that emotions somehow embody the information that their object has an evaluative property. In both Cognitivism and the Perceptual View, this information is embodied at the level of the contents of emotions. Emotions, whether they are evaluative judgments or perceptions of

\footnotetext{
${ }^{4}$ It follows that merely undergoing an emotion does not also make us aware of its evaluative nature. In fact, the latter point is in some circumstances trivial since one may plausibly undergo an emotion without being aware of it. For the sake of the argument, we therefore take our opponent as adopting the stronger thesis according to which even the awareness of an emotion does not make us aware of its evaluative nature.
} 
values, have evaluative contents. Having such an evaluative content is part of what it is to be an emotion. Hence, it follows that emotions have correctness conditions as a consequence of their intrinsic nature and more specifically their specific evaluative contents.

The distinguishing feature of the Attitudinal View is to renounce the idea that emotions have evaluative contents while maintaining that emotions have correctness conditions spelt out in evaluative terms. Since, on the latter view, the content of an emotion is not evaluative, it is in virtue of the complete correctness conditions of the emotional state that we are able to form a justified evaluative judgment. Although the content of the emotion is taken in as a part of the content of the evaluative judgment, the evaluative content is brought in the content of the judgment in virtue of the evaluative attitudes that emotions are. Consider a similar story with judgments about our perceptual experience. If I judge from my perceptual experience of an apple that I perceive an apple, my judgment does not simply take in the content of the perceptual experience (that there is an apple in front of me). Although it does take in the content of the perceptual experience, I must also be aware that I have a perceptual experience of an apple in order to form the judgment that I perceive an apple.

However, the analogy raises a problem. No doubt, the question of how a judgment that we have a specific perceptual experience can be justified or have the status of knowledge is of crucial importance. Analogous questions may be raised with other mental states. Consider for instance our memories: If I judge that I have a memory of my brother eating my cake, it makes sense to wonder how I am aware that I have a memory and not a perception or a mere thought with this content. Similarly, in order to judge that I am afraid of a barking dog, I must certainly rely on the awareness of my emotion itself and one may wonder what this awareness consists in. Be that as it may, the latter case shows that there is an important dissimilarity between, on the one hand, the perceptual and memory cases and, on the other hand, the case in which I form an evaluative judgment on the basis of my emotional experience. In the former cases, the part of the content of the judgment that goes beyond the content of the grounding experience states only the type of this grounding experience: that it is a perception or a memory. In contrast, when we consider the evaluative judgments that derive from our emotions, the contents of these judgments are not that we have an emotion of a given type with a non-evaluative content. Rather they are evaluative judgments. Hence, the following question arises: how can the experience of an emotion lead us to form and —at least partlyto ground an evaluative judgment? 
The claim which the Attitudinal View is committed to is that this transition is possible and may be justified because emotions are evaluative attitudes. However, it is of the utmost importance to keep in mind that the claim that emotions are evaluative attitudes is highly ambiguous. Hence, there is serious risk to slide from a modest and plausible claim to a strong and disputable one. In fact, the idea that emotions are evaluative attitudes or manifestly so can be given at least three interpretations from the weakest to the strongest.

First, there is the obvious fact that we experience our emotions as reactions or responses to the world triggered by specific objects in the environment. To this extent, emotions may certainly be considered evaluative attitudes. However, this consideration does not involve any normative reading of the notion of evaluation. In this sense, emotions may not even assess their object with regard to a value and no value is manifested in the experience of the emotion itself; we are merely saying that emotions are responses to objects and that these responses depend on some features of their object. Hence, it is no part of this claim that emotions have correctness conditions at all.

Second, there is the stronger claim that emotions are reactions or responses to the world with regard to certain standards, and it may even be claimed that we experience emotions as being such responses. Appraisal theorists (see, e.g., Scherer et al. 2001) hold versions of this claim although they diverge as to whether the appraisal and the standards (what they call "goal" or "concern") are accessed by the subject herself while she undergoes the emotions. Notice, however, that if these standards are not full-blooded values, this claim does not involve either a normative reading of the notion of evaluation. It does not follow from emotions being evaluative attitudes in this sense that they have correctness conditions in terms of values.

The third and strongest interpretation is what the defenders of the Attitudinal View must secure, namely that emotions are, or manifest themselves as, evaluations with regard to values. In sum, what we want to highlight is that even if one acknowledges that emotions are in some sense evaluative attitudes, only the strongest view may be of help for the Attitudinal View. In order to explain how emotions allow us to form evaluative judgments in some circumstances, the defender of the Attitudinal View must show either that emotions are manifestly evaluative in the strongest sense or how their intrinsic correctness conditions in terms of values allow us to form and at least partly justify evaluative judgments. 
In what follows, we shall therefore explore the only two possible avenues that are available to the defender of an Attitudinal View: either the evaluative information is manifest in the emotional experience or it is not. In the former case, the defender of the Attitudinal View owes us an explanation of how emotions appear as evaluative attitudes although their contents is non-evaluative. In the latter case, she must show us that although our emotions are not manifestly evaluative attitudes, it is in virtue of the fact that emotions have intrinsic correctness conditions that we are able to form and justify evaluative judgments. We shall argue that both paths are paved with serious obstacles.

\section{The Manifest Attitudinal View}

\subsection{Clarifications and commitments}

The first version of the Attitudinal View is what we shall call the Manifest Attitudinal View (or MAV for short). Like all versions of the Attitudinal View, MAV denies that emotions have evaluative contents. Values are not among the intentional objects of emotions. My emotion of fear is about the barking dog and not about the fact that the barking dog is dangerous. I do not fear danger; I fear the barking dog itself.

In denying that emotions have evaluative contents, MAV rejects the Perception View (or PV). However, it preserves a core component of PV, namely the view that emotions manifestly have evaluative correctness conditions. On this view, it is transparent to the subject, just by being emotionally involved with the world, that if her emotion is correct, a specific evaluative state of affairs is the case. Deonna and Teroni's (2012; this volume) are defenders of MAV. They clearly want the evaluative dimension of emotions to be reflected and even explained by their phenomenology. They write that "it is in virtue of their phenomenology that emotions relate to evaluative properties" (2012, p. 79). Another defender of MAV, at least with respect to some cases of emotional experience, is Crane (2007), who writes: "Objects are presented to us as meaningful in various ways, and part of this meaning is their affective significance: objects can seem loveable, valuable, in need of care, frightening or nauseating. This can be, depending on the case in question, an aspect of their content or an aspect of their intentional mode." (2007, p. 490). In this passage, Crane seems to advocate a mixed theory, where MAV applies to some cases while PV can be maintained for other cases. 
Both PV and MAV entail that emotions have a specific evaluative phenomenology. However, in contrast to $\mathrm{PV}, \mathrm{MAV}$ is committed to denying that the evaluative phenomenology of an emotion supervenes on its content. More specifically, if the content of an emotion is conceived as being constituted by representational properties of the emotion, MAV is committed to denying Representationalism, i.e., the view that the phenomenology of intentional mental states supervenes on their representational properties (see Tye 2000). The same content (e.g., that a dog is barking at me) can be apprehended through different emotional modes (e.g., fear or amusement), giving rise to different evaluative phenomenologies. So differences at the level of phenomenology cannot always be traced back to differences at the level of content (see Deonna and Teroni 2012, this volume). Part of the phenomenology of the emotion is provided by the content of the emotion (the barking dog), while another part is provided by the emotional attitude itself over and above its content, i.e., by what is sometimes called its "intentional mode", or "mode" for short (see Crane's quotation above).

A possible motivation for MAV and its commitment to an evaluative phenomenology is epistemological: it is to allow an evaluative judgment, such as the judgment that there is a dangerous barking dog around, to be fully grounded on the phenomenology of the underlying emotion. In this view, we do not have to rely on ancillary information or background beliefs in order to form, on the basis of our emotion of fear, the justified judgment that the barking dog is dangerous. Our judgment is a direct reflection of what it is like to fear a dog barking at us, and it is fully justified by the phenomenology of our emotion. Note, however, that a defender of MAV is not committed to such a view. For instance, she can contend more modestly that the object of the emotion must instantiate the value that is manifested in the attitude, in order to form a justified evaluative judgment. (The latter option is the one preferred by Deonna and Teroni 2012, pp. 119-120.)

\subsection{Is MAV a form of adverbialism or what else?}

The main challenge of MAV is to give an account of the phenomenology of emotion that meets the following two requirements. First, the phenomenology of emotion must be rich enough to be genuinely evaluative, in the strong, normative sense introduced above (\$2). For instance, the phenomenology of the experience of fearing a dog barking at us must reflect nothing less than the dangerousness of the dog. Second, on pain of collapsing into PV, the 
phenomenology of the experience must not be such that the subject is presented with the fact that the object of the emotion has a specific value. In other words, the genuine evaluative dimension of the phenomenology must come from the mode rather than the content.

In our opinion, MAV cannot meet both requirements at once. Consider the second requirement first. According to MAV, the evaluative dimension of the phenomenology of an emotion must reflect intrinsic non-representational properties of the emotion. On the one hand, it cannot reflect extrinsic properties since it is supposed to come from the emotion itself, independently of its contingent relations to other mental states. On the other hand, it cannot reflect representational properties, since it is supposed to come from the mode of the emotion and not its content. How is this possible? The most famous (or infamous) method of reducing apparently representational properties of an experience to non-representational ones is adverbialism. In the philosophy of perception, adverbialism is the attempt to explain away what seem to be intentional objects of our perceptual experiences in terms of modifications of these experiences (Sellars 1975). For instance, when I seem to see a barking dog, I am appeared to barking-ly and dog-ly, where the adverbs "barking-ly" and "dog-ly" are supposed to denote non-relational properties or modes of my visual experience. As a consequence, mental states do not involve genuine relations to intentional objects; what we ordinarily call the "contents" of mental states are fully determined by non-relational properties of the latter. Perceptual adverbialism in its standard form is notoriously plagued with serious objections (see, e.g., Jackson 1988), but one might try to defend a limited form of adverbialism, restricted to emotions and values. When I fear the barking dog, my emotion has a genuine intentional object, namely the barking dog. This object is in itself non-evaluative. However, in fearing the dog, I experience it fearsomely. The evaluative dimension of my emotion is not part of its content but shows up in the specific way in which I experience the world. ${ }^{5}$

Of course, like all forms of adverbialism, the proposed account must involve a proper definition of the semantic values of the relevant adverbs. Following a standard semantic analysis (Davidson 2001), adverbs denote properties of events. For instance, the adverbs "round-ly" and "red-ly" in "I am visually appeared to round-ly and red-ly" denote properties of my visual experience. These properties cannot be roundness and redness themselves, for my experience is neither round nor red. Similarly, my emotion of fear need not be itself fearsome or dangerous. Intuitively, the properties denoted by "round-ly", "red-ly" or

\footnotetext{
${ }^{5}$ See Döring (2014) for a discussion of an adverbialist account of emotions similar to the one presented here, which she attributes to Musil.
} 
"fearsome-ly" have some connection with roundness, redness, and fearsomeness, but the nature of this connection needs further clarification.

Let us assume that a plausible adverbialist account can be given of how an emotion can have an evaluative phenomenology without having an evaluative content. There is still an important difference between such an account and perceptual adverbialism. The aim of perceptual adverbialism was to get rid of the notion of intrinsic correctness conditions, by trying to show that the phenomenology of perceptual experience can be accounted for without positing intentional objects. As Siegel (2013) makes clear in her discussion of this account, it does not associate perceptual experiences and their modifications with "accuracy conditions", i.e., what we call here "correctness conditions". This is not in itself an objection against the proposed adverbialist account of the relationship between emotion and value, since adverbialism in general is arguably compatible with the view that the relevant kind of experience has intrinsic correctness conditions in addition to its non-representational phenomenology. However, what the foregoing discussion shows is that an account of the phenomenology of evaluation might not be enough to motivate the claim that emotions have intrinsic evaluative correctness conditions. As an analogy, consider the perceptual adverbialist account of the chromatic phenomenology of visual experience. One might argue that it captures what it is like to see a colored object, but that it is neutral as to whether the visual experience is intrinsically correct only if its object has the relevant color. Thus, the defender of MAV might have to give an additional argument for the claim, inherent to the Attitudinal View, that an emotion is correct only if its object has the relevant value.

This brings us to the first requirement that MAV has to meet, namely that the phenomenology of emotion must be genuinely evaluative. One might wonder how an emotion could have such a rich phenomenology. For an emotion of fear to be manifestly correct if its object is fearful or dangerous, the relevant value must be bound to the object at the level of the conscious emotion itself. Of course, it cannot be bound within the content of the emotion (as in PV). Now if the evaluative phenomenology of the emotion is accounted for in terms of non-representational properties, it follows that undergoing an emotion cannot make us aware that its object, say a barking dog, is fearful or dangerous. At best, we are aware of the emotion itself as valuing in a way or other, but not that it is correct only if the dog is fearful or dangerous. In short, knowing emotional ways of valuing the world do not by themselves yield knowledge of what must be the case in the world in order for our emotions to be correct. As an analogy, according to perceptual adverbialism, knowing ways of seeing do not by 
themselves yield knowledge of what must be the case in the world in order for our visual experiences to be correct, i.e., veridical.

In Deonna and Teroni's (2012, this volume) view, the phenomenology of emotions is best captured in terms of bodily feelings. More precisely, they claim that "we should conceive of emotions as distinctive types of bodily awareness, where the subject experiences her body holistically as taking an attitude toward a certain object" $(2012,79)$. In a later essay, they also suggest that "[m]aking reference to the subject's consciousness of a given readiness to act indeed allows one to develop a fine-grained understanding of the claim that it is because emotions are felt bodily attitudes of a certain type that they possess evaluative correctness conditions" (see this volume, cf. ms pp. 16-17). For instance, when we fear the dog barking at us, we are conscious of our characteristic response to an external object (the barking dog). However, we might agree with their phenomenological characterization of the relevant response while denying that what we are aware of while undergoing an emotion is that the emotion is correct if its object has the relevant value. Even if we grant, for the sake of argument, that emotions involve a phenomenology of evaluation in the normative sense, the problem is that the awareness of myself valuing as dangerous or fearsomely the dog does not entail the awareness of the dog itself as dangerous or fearsome if the evaluation is not part of the content of the emotion. This entailment holds only if my evaluation is somehow experienced as being correct or not. But merely having an emotion, if it is construed along the lines of MAV cannot make me aware that my emotional evaluation valuation of the world has correctness conditions. Viewed in this way, my emotion cannot ground the world-directed evaluative judgment that the barking dog is dangerous. At best it can ground the self-directed judgment that the barking dog is currently evaluated as dangerous (by me). In other words, being aware that I am experiencing the dog fearsomely or amusingly falls short of being aware that my emotion is correct only if the dog is fearsome or amusing. I am aware at best that my emotion is evaluative, or involves a specific evaluation of the dog as fearsome or dangerous. It does not follow that I am aware that unless my emotion is incorrect, the dog is in fact dangerous or fearsome. ${ }^{6}$

\footnotetext{
${ }^{6}$ It seems to us that many of the objections that we have raised against the thesis that emotions present their objects as having evaluative properties (Dokic and Lemaire 2013) may be transferred to MAV. In particular, we have argued that it is difficult to make sense of the idea that the bodily manifestation of an emotion presents a value since after all, the perception of my body and its doings are in no way normative. Moreover, one may wonder how the thesis that emotions manifest their evaluative nature rather than present evaluative properties helps to overcome the foregoing difficulties. How is this thesis supposed to explain how we grasp the value element in our emotional experience?
} 
To put the same point slightly differently, MAV requires that it be manifest to the subject, just by having an emotional experience, that the emotion is correct only if its object has the relevant value. The relevant phenomenology is fixed by either representational or nonrepresentational properties of the emotion. The former alternative leads us back to PV: by having the emotional experience, the subject is aware that the object of the emotion has the relevant value. In other words, the evaluative state of affairs is represented through the emotion. The latter alternative leaves a gap between the evaluative phenomenology of emotion and its supposed intrinsic evaluative correctness conditions. To bridge the gap, the defender of MAV must show that the emotional experience involves an experiential binding of the relevant value to the object of the emotion. Again, MAV runs the risk of collapsing into a version of PV. All in all, if we accept that emotions involve a phenomenology of value in the normative sense, $\mathrm{PV}$ is in a much better position than MAV. The main challenge faced by MAV is still there: how can emotions have the appropriate evaluative phenomenology unless they manifestly present evaluative states of affairs to the subject?

\section{The Opaque Attitudinal View}

In the previous section, we have shown that it is hard to make sense of the idea that emotions manifest themselves as being evaluative while denying that they have evaluative contents. In order to avoid this difficulty, the friend of the Attitudinal View might claim that although emotions are evaluative attitudes, they are not manifestly so. As far as we know, nobody has yet defended this view, which we call the Opaque Attitudinal View (or OAV for short). The difficulties faced by MAV may fuel the interest in OAV, since the latter view seems to be the last resort if one wants to hold that emotions have intrinsic links to values. Moreover, we believe that our discussion of OAV will expose the kind of illegitimate move that gives initial plausibility to the idea that emotions have intrinsic norms, whereas more careful consideration reveals these norms as being extrinsic.

The main challenge that OAV faces is obviously to explain how emotions can justify evaluative judgments or at least contribute to ground evaluative judgments if their evaluative nature is not manifest. In order to answer this challenge, it seems that the friend of OAV has only two options. One option is to claim that it is rational to make direct transitions from emotions to evaluative judgments. The other is rather to claim that these transitions are 
rational given some awareness of the evaluative nature of emotion, where this awareness does not derive directly from the experience of our emotions.

We will show, however, that OAV is unable to show that such rational transitions exist while maintaining that the correctness conditions of emotions are intrinsic. Put the other way round, we will argue that either these transitions are not rational or they need eventually to rely on normative considerations that are not derived from the nature of emotions themselves. The next two subsections present these difficulties.

\subsection{The rational sensitivity strategy}

OAV insists that emotions have intrinsic evaluative correctness conditions but admits that evaluative judgments cannot be fully grounded on the phenomenology of emotions. This raises the question of how we can form evaluative judgments on the basis of our emotional experiences. This question has two related aspects, psychological and epistemological. From the psychological point of view, we want to know the nature of the transition from emotions to evaluative judgments. From the epistemological point of view, we want to know whether evaluative judgments can be justified or warranted and the role of emotions in their justification or warrant.

Let us continue with our example of the barking dog. We certainly on some occasion move from our fearing the barking dog to the evaluative judgment that the barking dog is dangerous. However, according to proponents of the Attitudinal View, the content of the emotion does not involve the presentation of anything as being dangerous. In Peacocke's vocabulary, this is to say that, in the latter judgment, the use of the concept of danger is "representationally independent", in the sense that it is not the re-deployment of something that already figures in the content of the underlying emotion (see Peacocke 1999, 6.1). The content of the emotion does not involve the presentation of anything as being dangerous. Of course this is not in itself an obstacle to considering the evaluative judgment as being justified by the fear of the barking dog. In general, representational independence is compatible with the judgment being justified by the underlying conscious state. For instance, my fearing the dog can justify a self-ascription of the form "I am afraid of the dog", where the use of the concept of being afraid is representationally independent. 
The crucial question is nevertheless whether an evaluative judgment can be justified by an emotion as the emotion justifies the self-ascription of the emotion. As Peacocke (1999, see for instance p. 216) observes, representational independence is based on rational sensitivity to the kind of mental state which constitutes the reason for forming the judgment. Thus, my conscious emotion can at best ground judgements about the attitude of fearing, such as the judgement that I am afraid of the dog. Now, this rational sensitivity may be extended to justify judgments such as "I am evaluating the dog in being afraid" understood as meaning "I am responding to the dog with fear". However, as we have seen, there is a logical gap between the self-directed judgment that I am responding with fear and the world-directed judgment that the dog is dangerous.

At this point, the defender of OAV can insist that the judgment that the dog is dangerous is sensitive to the intrinsic correctness conditions of the underlying emotion, even though they do not surface at the level of phenomenology. Since my emotion is correct only if the dog is dangerous, I can judge that I am responding in a certain way to the dog's dangerousness, which entails the belief that the dog is dangerous. However, this move seems entirely ad hoc, since it is warranted only by the claim that emotions have intrinsic evaluative correctness conditions. It thus makes it completely mysterious why the subject is led to make an evaluative judgment out of an emotion whose awareness has no evaluative component. In other words, neither the content nor more generally the phenomenology of emotions can explain the rationality of the relevant transition. How is it that the agent introduces an evaluative concept at the level of judgment? As Peacocke acknowledges, there are cases in which short-cuts are allowed, such as the self-ascription of a memory in the absence of any apparent memory. However, the rationality of this kind of self-ascription requires that it be possible to experience a relevant apparent memory. If this longer route is not available, then the sensitivity does not earn the right to be called "rational" (Peacocke 1999, p. 217). But this is precisely what we are asked to accept in the evaluative case insofar as the evaluative concept that is representationally independent is not grounded in emotional experience or in any of its aspects.

Note that the defender of OAV can consistently concede that emotions are not sufficient reasons of forming evaluative judgments. She can claim that although there is no direct rational sensitivity to the intrinsic correctness conditions of emotions, evaluative judgments may also rely on collateral information (explicitly or implicitly). For instance, the judgment that the dog is dangerous, or that the joke is funny, is based not only on a conscious 
emotion of fear or amusement, but on extraneous considerations to the effect that the emotion is, in the relevant circumstances, correct. Now, these extraneous considerations do not raise as such a problem for the defender of OAV. She may argue that the conditions under which an emotion is correct are usually known, ${ }^{7}$ and that, when the subject is aware that such conditions are instantiated, she is allowed to derive an evaluative judgment from her emotional experience.

The crucial question at this juncture is whether the correctness conditions are known by some sort of inquiry that reveals that our emotions have intrinsic correctness conditions or whether they are known by derivation from norms that are extrinsic to emotions. In other words, the Attitudinal View faces an obvious alternative, which is that the only norms that we come to know and that we apply to emotions are eventually extrinsic norms or reasons. The nature of these norms is a matter of further investigation but they could be moral or prudential, or even (in some cases) aesthetical. For instance, one may argue that if we believe that the emotion of fear is correct in response to dangerous objects, this is in fact merely because we recognize the importance of prudential considerations. And clearly, prudential reasons apply extremely broadly and need not characterize correctness conditions intrinsic to fear. Similarly, one may argue that if we believe that admiration is appropriate to some objects and not to others, this is because we recognize aesthetical or moral norms, norms that apply again very broadly and which are certainly not intrinsic to admiration. On such a view, the evaluative judgment would be partly grounded on our emotion, but also, as far as its evaluative part is concerned, on extraneous evaluative or normative considerations. The challenge for the defender of OAV is therefore to show that this alternative view is inferior to his or her own account. In a commentary to a previous version of the present paper, Deonna and Teroni suggested to us that they in fact "assume" that emotions have intrinsic correctness conditions. But we might wonder: is this assumption true? Furthermore, are we relying, and are we justified in relying, on this assumption when we make evaluative judgements on the basis of emotions? If this is not the case, then even if the Attitudinal View may still contend that emotions have intrinsic correctness conditions, the fact that they would play no role in our understanding of emotions would be a serious objection against the assumption insofar as it becomes idle.

\footnotetext{
${ }^{7}$ For simplicity, we will keep speaking of knowledge but as Pettit (1991, pp. 604-605) has suggested with respect to color experience and color judgment, this knowledge may be ingrained in a practical capacity, a form of know-how rather than an explicit knowledge. On the nature of this knowledge, we will however stay neutral.
} 
In order to avoid the objection, the defender of OAV has to insist that evaluative judgments grounded in emotions rely on the subject's knowledge of evaluative correctness conditions that are intrinsic to her emotions. As we will presently try to show, there is no such knowledge.

\subsection{Knowledge of correctness conditions}

How do we know that emotions have correctness conditions? More specifically, how do we know that a certain type of emotion has correctness conditions in terms of a specific value? Recall that we must have such knowledge in order to explain how the transition from an emotional experience to an evaluative judgment is possible and can be justified. As we will see, however, there is a serious difficulty as to how this knowledge is acquired. To see this, one must be reminded that these correctness conditions are not known from the consideration of emotions themselves. If this were possible, then emotions would manifest themselves as being evaluative attitudes. In other words, we would be brought back to MAV. Therefore, one must suppose that the correctness conditions of emotions are not discovered by considering the emotions alone. We will consider in turn the two options available, depending on whether these norms or correctness conditions are supposed to be known a priori or a posteriori.

On the first option, the correctness conditions of each emotion type would be known $a$ priori, as part of the conceptual knowledge of each emotion type. Consider, as a comparison, the case of belief. Some philosophers claim that beliefs involve intrinsic norms or have correctness conditions. For instance, they suggest that one ought to believe that $p$ if and only if (or only if) $p$ is true (Shah 2003, Engel 2013) or that a belief is correct (in a normative sense) if and only if the belief is true (Mulligan 2007). ${ }^{8}$ Now, some of these philosophers also claim that these norms or correctness conditions are known as part of our mastery of the concept of belief. Could we extend this idea to emotions? Yes, we might say, taking inspiration from Peacocke (1992) or in agreement with Mulligan (1998). We might suggest that it is part of the possession conditions of the concepts of fear and danger that we are "primitively compelled" to move from an experience of fear to the judgment that its object is dangerous at least in normal conditions. Similarly, Mulligan writes that " $[\mathrm{t}] \mathrm{o}$ understand an

\footnotetext{
${ }^{8}$ There is an important ongoing debate on the formulation of the norms or correctness conditions of beliefs. The formulations that we give here are only for illustrative purpose. We do not commit ourselves to any specific account nor even to the very existence of such norms or correctness conditions.
} 
axiological predicate is to be familiar with the range of emotional experience which stand in relations of prima facie justification to uses of the predicate." (1998, p. 172). ${ }^{9}$ Another and more "intellectualist" suggestion is that the mastery of the concepts of fear and danger requires that one find primitively compelling that fear is correct if and only if its object is dangerous.

The problem with this view is that, as the discussion in the previous section should already have indicated, we have no reason to believe that our concept of fear involves a priori such specific possession conditions. For instance, it is unclear why the concept of fear would involve our commitment to transitions from fear toward a given object in normal conditions to the judgment about the dangerousness of this object insofar as we are not aware of danger through fear as OAV conceives it. For the same reason, why should the possession conditions of the concept of danger allow transitions from fear to judgments about danger? To take another example, it is certainly not part of the possession conditions of our concept of contamination that experience of disgust allows judgment to the effect that its object is potentially contaminating.

In response, it might be said that, at least, possession of the concept of fearsomeness makes us primitively compelled to move from an experience of fear toward an object when the correctness conditions are satisfied to the judgment that the object is fearsome. The problem is that even if propositions such as "If one experiences fear toward an object when the correctness conditions are satisfied, then the object is fearsome (i.e., correctly feared)" are a priori, they do not inform us as to which kind of norms or correctness conditions we should consider in order to determine whether a particular emotion of fear is correct. Certainly, we can form an a priori general representation of the conditions that would make fear required from the perspective of etiquette, or from the perspective of prudential or even moral norms, but the problem is that OAV implies that emotions themselves do not tell us which kinds of norms are supposed to be intrinsic. Even if we focus on norms of correctness, the proposition is uninformative since precisely emotions do not tell us what makes them correct. In short, the problem is that we have no means to identify what would be the intrinsic norms of emotions, or the kind of correctness that is supposed to be intrinsic to emotions.

All these considerations show that the correctness conditions of emotions cannot be known a priori. However, there is a second option available to the defender of the correctness

\footnotetext{
${ }^{9}$ See also Deonna and Teroni (2012, p. 83).
} 
conditions. She can accept all the foregoing and insist that it only shows that the correctness conditions are known a posteriori. In fact, this is certainly a plausible line of thought and it has indeed been pursued, in particular with regard to color properties. Suppose that you hold a dispositionalist theory of color properties according to which an object is red if and only if it appears red under normal conditions. It is not very plausible to suggest that we know a priori what the normal circumstances that justify the move from the experience of the object as appearing red to the judgment that the object is red are. Rather, it has been suggested (Pettit 1991, Tappolet 2000, pp. 217-218) that we learn by experience how the circumstances modify color appearances. For instance, we learn that a table that appears white in daylight appears red if it is enlightened with red light, we learn that it is harder to determine its color at night, etc. Building on such experiences and similar others, certain conditions emerge as normal and as the ones which justify the move from a color experience to a color judgment. In other words, the normal or correctness conditions are known a posteriori insofar as they have been taught to us by experience. Notice, however, that this is perfectly compatible with the proposition "An object is red if and only if it appears red in normal conditions" being firstly $a$ priori. The two are compatible precisely because one may first accept the proposition on conceptual grounds but then make it an a posteriori truth by offering a substantial characterization of the normal conditions.

Could we understand the knowledge of the correctness conditions of emotions along similar lines? To the extent that we assess the correctness or appropriateness of emotions, the strategy is prima facie workable. Let us have a further look at the practice that assesses the correctness of emotions. In fact, it seems that there are two practices or a twofold practice: we may call these practices the discarding practice and the deliberative practice. The former consists in discarding experienced emotions as unsuitable to ground an evaluative judgment. For instance, if I laugh at a certain joke while being drunk, I may myself acknowledge that there is in fact nothing funny to laugh at and that I have been somehow erroneously drawn to laugh. Building on Pettit (1991), D'Arms and Jacobson (2010) have substantially specified how such a practice could work. The other practice is the deliberative practice in which one deliberates over the emotion that one should have in response to given objects in given circumstances. Although this practice has come to play a central role in arguing that beliefs are intrinsically normative (Velleman 2000, Shah 2003, Engel 2013), its importance has been less emphasized with regard to emotions. ${ }^{10}$ Nevertheless, one may argue that its conclusion

\footnotetext{
${ }^{10}$ But see Lemaire (2014).
} 
could help us to determine the correctness conditions of each emotion type. Let us finally notice that these practices are in fact two aspects of the same practice, which assesses the appropriateness of emotions as responses to objects. The only difference is that in the discarding practice we start from an experienced emotion and wonder whether it was appropriate to have this emotion in response to its object, whereas in the deliberative practice this does not seem to be required insofar as we often start from the consideration of an object and wonder which emotion would be appropriate. For simplicity, we will refer to both practices as deliberative ones.

Given the obvious existence of deliberative practices, the main difficulty remains to understand how we can conduct them without being beforehand aware of the norms that apply to emotions. As we have seen, the case of color may offer us a model. But there are two major objections to such a transposition. First, it is important to see that the story proposed above about the discovery of the normal conditions of color experience is incomplete. After all, one might wonder why the circumstances that are considered normal are not those in which an object is enlightened by red or any other colored light. The response is in part that daylight lightening is normal because it is a circumstance under which colors are more easily discriminated. If that were all, it would certainly contribute to justify that color experience are correct in certain favourable circumstances. Unfortunately, normal people differ in their color experience and there are different circumstances that would be optimal for the discrimination of colors. ${ }^{11}$ In deciding that certain subjects and circumstances are the normal ones, we are therefore introducing a certain amount of arbitrariness. In the case of color, the fact that day light is the most ordinary shows also that pragmatic considerations play a substantial role in the determination of the conditions under which the color appearance of an object will be taken as correct. Now, the problem is that such pragmatic considerations cannot be relevant in the determination of the conditions under which an emotional experience is correct and would thereby ground an evaluative judgment. That an object is valuable cannot be decided by the mere fact that it is more manageable to consider some circumstances as those in which an emotion is correct. For instance, it cannot be decided that envy is correct in certain circumstances simply because these circumstances are the general circumstances in which one is envious. That would be a transition from an 'is' to an 'ought'. In addition, it would follow that the determination of the correctness conditions depends on pragmatic considerations that

\footnotetext{
${ }^{11}$ These points have been forcefully argued by Hardin (1988) and has led Cohen (2004) to argue that the only plausible form of dispositionalism is relational in which case the color blue is superseded by such colors as bluefor-perceiver A-in-circumstances $\mathrm{C}$ 1, blue-for-perceiver B-in circumstances $\mathrm{C} 2$, etc.
} 
are not, after all, intrinsic to emotions. Considerations of simplicity or about what is manageable are not intrinsic to emotions but obviously general norms that are thereby extrinsic to emotions. Notice also that they are plausibly some sort of practical norms or derived from such norms.

There is a second and more serious problem with the color analogy. In the case of color, the correctness conditions that are empirically discovered are those of a perceptual experience. In other words, the property that is attributed to the object of our experience in correct conditions is presented in the experience. But, on OAV, no value is presented in the emotional experience since it is precisely the point of this view that emotions do not make us directly aware of their evaluative nature. We are therefore back to the same recurrent problem: we have no idea of the kind of objects that would make an emotion of a certain type correct. We do not even know that emotions are evaluative in the strongest sense if they are. But if we do not know that they are evaluative, how are we supposed to discover it? Let us even suppose that emotions are normally responses to values. It would not follow that they are correct when they respond to the values to which they normally respond. In a nutshell, the problem is that the defender of OAV is unable to explain how we can know a posteriori that the correctness conditions of emotions relate them to values and not to anything else.

In order to face this challenge, the unique possible move is to suggest that each type of emotion although not manifestly evaluative is best fitted as a response to a type of value. We could discover when emotions are correct because we could discover the evaluative situation in the world to which each type of emotion is best fitted.

This is certainly a promising line of thought but not one that the defender of emotions as evaluative attitudes can accept. The Attitudinal View cannot be vindicated if one introduces in the analysis a normative notion that is not required by the intrinsic nature of emotions as far as they are experienced by the subject. To see this, consider the most obvious way to flesh out the above proposal, which is to claim that an object being dangerous is the condition that makes fear correct because fear is an efficient response from a prudential perspective to dangerous objects. This certainly sounds true but we are still saddled with the same problem. Even if this assessment of fear seems more relevant than other possible evaluative perspectives, it does not show that it is more intrinsic to fear than an assessment from a moral, aesthetical, or indeed any normative point of view. Compare: even if it is more relevant to assess the action of diving from a cliff from a prudential perspective than from any 
other normative perspective, this does not make the prudential norms intrinsic to the considered action. ${ }^{12}$ To put the same point the other way round, the problem is that OAV in and of itself makes it impossible to show in a non-begging way which norms are intrinsic to emotions. To our mind, one of the possible reasons that may have led philosophers to contend that emotions have intrinsic correctness conditions is that some norms seem more relevant than others. But as we have just argued, we do not see what justifies the leap from the latter remark to the former thesis. In addition, even if it were true that emotions have intrinsic correctness conditions, the epistemic route that we have just sketched to explain how one would acquire the correctness conditions of emotions would still start from norms that are generally accepted, apply broadly and therefore are external. Hence, here again, it seems that we would be left with a curious gap between an ontology and an epistemology that does not rely on the ontology.

The defender of the evaluative nature of emotions might respond that we can discover the correctness conditions of emotions if we put aside the extrinsic normative considerations that we have just considered. Along this line, it has been argued that the correctness conditions of envy must be understood in terms of what is enviable. But how could that work? Let us exclude prudential, moral and aesthetical norms as being irrelevant. ${ }^{13}$ What are we left with? How could we empirically discover that fear is correct as a response to danger and that envy is correct as a response to the enviable? It seems to us that the only two solutions that remain available are to argue either that the function of fear is to face danger or that fear results from or encompasses ${ }^{14}$ an evaluation of its object as being dangerous ${ }^{15}$ although the subject who undergoes the emotion may not be aware of that evaluation. One may then derive from the function of emotions or from the evaluation they involve that they represent values from a teleosemantic approach. ${ }^{16}$ One could then argue that emotions have intrinsic correctness conditions and that these intrinsic correctness conditions derive from the function of emotions from an evolutionary point of view, or from their cognitive nature. Moreover,

\footnotetext{
${ }^{12}$ Interestingly, this example reveals that an aesthetical norm may be more relevant than other kinds of norm in some circumstances.

${ }^{13}$ Along similar lines, D'Arms and Jacobson (2000) have indeed suggested that emotions have correctness conditions in terms of values that need to put aside prudential and moral reasons.

${ }^{14}$ A referee has suggested to us that if the evaluation that produces emotions is not part of them but is merely a condition for their appearance, then it follows that emotions have no more intrinsic correctness conditions. Their correctness becomes at best derivative on these evaluative processes. Although true, we are not pressing this point since our final claim is that the cognitive process of evaluation that is involved in or required by emotions has no intrinsic correctness conditions in terms of values in the normative sense.

${ }^{15}$ As most defenders of the Appraisal theory of emotion argue. For an overview, see Scherer et al. (2001).

${ }^{16}$ See especially Dretske (1991).
} 
these facts could be empirically discovered or maybe could entitle someone who undergoes an emotion to judge that the object of the emotion may have or has (maybe in virtue of additional information) the value corresponding to the type of emotion she undergoes.

The well-known problem of these strategies is however that they move from an 'is' to an 'ought'. For sure, it is extremely plausible that each type of emotion has the function to represent a certain set of states of affairs but it does not follow that these states are valueladen. Similarly, emotions certainly imply a cognitive evaluation of the environment, but it does not follow that this evaluation is done with regard to standards that we should consider as values in a normative sense. Plausibly, the environment is assessed in relation to certain goals that have been determined by evolution and to some extent by the history of each individual, but it is a completely different point to say that these goals are value-laden.

In summary, OAV is unable to explain how we could come to know a priori or $a$ posteriori that emotions have intrinsic correctness conditions in terms of values or that they are subject to norms that should be regarded as intrinsic. What seems to be the case, on the contrary, is that our emotions can be assessed from various general and extrinsic norms even if eventually, some normative perspectives are more susceptible than others to produce interesting assessments.

\section{Conclusion}

Cognitivism and the Perceptual View, which both claim that emotions have evaluative contents, have recently come under growing criticism. Under this pressure, those who believe that emotions are deeply tied to values may be prone to retract and hold a more modest view, the Attitudinal View, according to which emotions have correctness conditions in terms of values although these correctness conditions are not fully determined by the contents of emotions. The aim of this paper has been to assess this interesting move, which deserves to be more fully understood. Part of our contribution has been to point out that two avenues are open in order to fulfill this program, depending on whether it is claimed that we are aware of the evaluative nature of emotions while we experience them. We have shown that each avenue is plagued with difficulties.

If one wants to maintain that emotions manifest their evaluative nature, it seems that the Perceptual View is more plausible insofar as it is hard to see how emotions themselves can 
make us aware of the fact that they are correct in response to value while denying that emotions present values. On the other hand, if emotions themselves are not manifestly evaluative, we have shown that there is a serious epistemological challenge, which is that the subject has no means to identify norms or correctness conditions in terms of values that would be intrinsic to emotions.

If we were allowed to combine the present conclusion with the objections which we have raised against the Perceptual View (Dokic and Lemaire 2013) and those that have been raised against Cognitivism in the literature (cf. especially Stocker 1996, Tappolet 2000), we would conclude that the general view that emotions have intrinsic correctness conditions in terms of value is mistaken and should be given up. ${ }^{17}$

\section{References}

Cohen, J. 2004, "Color properties and color ascriptions: A relationalist manifesto", Philosophical Review 113.4 pp. 451-506.

Crane, T. 2007, “Intentionalism”, In Ansgar Beckermann \& Brian P. McLaughlin (eds.), Oxford Handbook to the Philosophy of Mind, Oxford University Press, pp. 474-493.

D'Arms, J. and Jacobson, D. 2000, “The moralistic fallacy: on the 'appropriateness' of emotions", Philosophical and Phenomenological Research 61.1, pp. 65-90.

D'Arms, J. and Jacobson, D. 2010, "Demystifying sensibilities: sentimental values and the instability of affect", in P. Goldie, ed., Oxford Handbook of Emotions, Oxford: Oxford University Press, pp. 585-613.

Davidson, D. 2001, “Adverbs of Action" (1985), in Essays on Actions and Events, Second Edition, Oxford: Clarendon Press, pp. 293-304.

Deonna, J. and Teroni, F. 2012, The Emotions: A Philosophical Introduction, London: Routledge.

\footnotetext{
${ }^{17}$ We are especially grateful to Jean-Moritz Mueller, Julien Deonna and Fabrice Teroni from whom we received extremely useful and extensive remarks. The paper has also benefited from the discussion with the audience at the Emotion and Perception conference held in Tuebingen in Nov. 2012.
} 
Deonna, J. and Teroni, F. ms., "Emotions as Attitudes”. This volume.

Dokic, J. and Lemaire, S. 2013, Canadian Journal of Philosophy 43, pp. 227-247.

Döring, S. 2009, "The logic of emotional experience: Noninferentiality and the problem of conflict without contradiction", Emotion Review 1.3, pp. 240-247.

Döring, S. 2014, "What Is an Emotion? Musil’s Adverbial Theory", The Monist 97, Special issue on the Philosophy of Robert Musil, pp. 47-65.

Dretske, F. I. 1991, Explaining behaviour: Reasons in a world of causes, Cambridge (Mass.): MIT press.

Engel, P. 2013, “In defense of normativism about the aim of belief”, in T. Chan, ed., The Aim of Belief, Oxford: Oxford University Press.

Jackson, J. 1988, “The Existence of Mental Objects”, in J. Dancy, ed., Perceptual Knowledge. Oxford Readings in Philosophy, Oxford: Oxford University Press.

Hardin, C. L. 1988, Color for philosophers: Unweaving the rainbow. Hackett Publishing.

Lemaire, S. 2014, "Norms for emotions: intrinsic or extrinsic?”, in J. Dutant, D. Fassio and A. Meylan, eds., Liber Amicorum Pascal Engel, University of Geneva, pp. 828-843. URL http://www.unige.ch/lettres/philo/publications/engel/liberamicorum

Nussbaum, M. C. 2001, Upheavals of thought: The intelligence of emotions, Cambridge MA: Cambridge University Press.

Mulligan, K. 1998, “From appropriate emotions to values”, The Monist, 81.1, pp. 161-188.

Mulligan, K. 2007, “Intentionality, knowledge and formal objects”, Disputatio, II/23, pp. 206-228.

Peacocke, C. 1992, A Study of Concepts, Cambridge MA: MIT Press.

Peacocke, C. 1999, Being Known, New York: Oxford University Press.

Pettit, P. 1991, “Realism and Response-Dependence”, Mind 100, pp. 587-626.

Scheler, M. (1970), The Nature of Sympathy, trans. P. Heath, New York: Archon Books. 
Scherer, K. R., Schorr, A. E., and Johnstone, T. E. 2001, Appraisal processes in emotion: Theory, methods, research, Oxford: Oxford University Press.

Sellars, S. 1975, “The adverbial theory of the objects of sensation”, Metaphilosophy 6, pp. 144-160.

Shah, N. 2003, "How truth governs belief”, The Philosophical Review 112, pp. 447-482.

Siegel, S. 2013, "The Contents of Perception”, in E. N. Zalta, ed., The Stanford Encyclopedia of Philosophy (Fall 2013 Edition), URL = $<$ http://plato.stanford.edu/archives/fall2013/entries/perception-contents/>.

Solomon, R. 1993, The Passions: Emotions and the Meaning of Life, Indianapolis: Hackett.

Stocker, M. 1996, Valuing emotions, Cambridge: Cambridge University Press.

Tappolet, C. 2000, Emotions et Valeurs. Paris: Presses Universitaires de France.

Tye, M. 2000, Consciousness, Color, and Content, Cambridge, MA: MIT Press.

Velleman, D. 2000, “On the Aim of Belief”, in The Possibility of Practical Reason, Oxford: Clarendon Press, pp. 44- 81. 